\title{
Investigation of eluted monomers from resin-based root canal sealer by high-performance liquid chromatography analysis
}

\author{
Huma Omurlu ${ }^{1}$, Hacer Deniz Arisu ${ }^{1}$, Evrim Eliguzeloglu Dalkilic ${ }^{2}$, Ugur Tamer $^{3}$, Hilal Torul ${ }^{3}$
}

Correspondence: Dr. Evrim Eliguzeloglu Dalkilic

Email: eeliguzeloglu@hotmail.com

\begin{abstract}
'Department of Restorative and Dentistry, Faculty of Dentistry, Gazi University, Ankara, Turkiye, 2Department of Restorative Dentistry, Faculty of Dentistry, Yeni Yüzyıl University, İstanbul, Turkiye, ${ }^{3}$ Department of Analytical Chemistry, Faculty of Pharmacy, Gazi University, Ankara, Turkiye
\end{abstract}

\section{ABSTRACT}

Objective: The purpose of the current study was to determine the amount of urethane dimethacrylate (UDMA), bisphenol A-glycidyl methacrylate (Bis-GMA), poly (ethylene glycol) dimethacrylate (PEGDMA), bisphenol A ethoxylated dimethacrylate (Bis-EMA), and 2-hydroxyethyl methacrylate (HEMA) eluted from resin-based root canal sealer, epiphany, using high-performance liquid chromatography (HPLC). Materials and Methods: Epiphany was placed into the plastic molds and light-cured with a light emitting diode. After the curing process, each specimen in the first group $(n=12)$ was immersed in Eppendorf tubes containing a phosphate-buffered saline solution (PBS) and incubated for $45 \mathrm{~s}$. In the second group, each specimen $(n=12)$ was immersed in Eppendorf tubes containing PBS and incubated for $24 \mathrm{~h}$. Of the specimen extracts, $100 \mu \mathrm{L}$ were subjected to HPLC. Analysis of data was accomplished with one-way analysis of variance $(P<0.05)$. Results: All of the samples eluted HEMA, UDMA, Bis-GMA, PEGDMA, and Bis-EMA. A significant difference was determined between the time periods of HEMA, UDMA, PEGDMA, and Bis-EMA $(P<0.05)$. Conclusion: The results of the current study showed that Epiphany releases HEMA, UDMA, Bis-GMA, PEGDMA, and Bis-EMA in both time periods.

Key words: High-performance liquid chromatography, monomer, resin, sealer

\section{INTRODUCTION}

Residual monomer, caused by the unfinished transformation of monomers into the polymer, can cause irritation, inflammation, and an allergic reaction of the oral mucosa. ${ }^{[1]}$ According to several in vitro studies, some of these monomers showed cytotoxic, genotoxic, mutagenic, or estrogenic effects and pulpal or gingival reactions. ${ }^{[2-4]}$ The greatest commonly used monomers for the preparation of resin-based materials are bisphenol A-glycidyl methacrylate (Bis-GMA), urethane dimethacrylate (UDMA), and bisphenol A ethoxylated dimethacrylate (Bis-EMA). These monomers influence the reactivity, viscosity, polymerization shrinkage, and water uptake of the material. ${ }^{[5]}$ Bis-GMA, a widely used component, has very good mechanical properties after curing. In previous studies, researchers reported that Bis-GMA and UDMA caused high cytotoxicity. ${ }^{[6-8]}$
Geurtsen et al. ${ }^{[7]}$ determined that Bis-GMA, UDMA, and Bis-EMA were cytotoxic to human fibroblasts.

High-performance liquid chromatography (HPLC) is usually used to determine the quality and quantity of the residual monomers eluted from dental resin materials. ${ }^{\left[{ }^{[9-16]}\right.}$ The current study used resin-based root canal sealer Epiphany and HPLC determined

This is an open access article distributed under the terms of the Creative Commons Attribution-NonCommercial-ShareAlike 3.0 License, which allows others to remix, tweak, and build upon the work non-commercially, as long as the author is credited and the new creations are licensed under the identical terms.

For reprints contact: reprints@medknow.com

How to cite this article: Omurlu H, Arisu HD, Dalkilic EE, Tamer U, Torul $\mathrm{H}$. Investigation of eluted monomers from resin-based root canal sealer by high-performance liquid chromatography analysis. Eur J Dent 2016;10:92-6.

DOI: $10.4103 / 1305-7456.175691$ 
the quantity of the residual monomers eluted from this material. Epiphany/Resilon's (Pentron Clinical Technologies, Wallingford, CT, US) obturation system consists of the core material (Resilon), the dual-cure resin-based root canal sealer (Epiphany Root Canal Sealer) and a self-etching primer. A lot of studies have covered the sealing ability of Epiphany/Resilon and fracture resistance of teeth using Epiphany as root reinforcements. ${ }^{[17-21]}$ However, no information is available about the amount of monomer release of this resin-based endodontic sealer. The biocompatibility of endodontic sealers and core materials are important to the progress of root canal treatment. Sjogren et al. ${ }^{[22]}$ reported that the long-time reaction of the periradicular tissues to cytotoxic materials may delay periapical healing and cause failing of endodontic treatment. Orstavik et al. . $^{[23]}$ and Waltimo et al. ${ }^{[24]}$ claimed that even in the lack of extrusion, endodontic sealers frequently directly contact adjacent periradicular tissues.

Leaching of residual monomers from resin-based material not only affects its biocompatibility but can also decrease the mechanical properties of the resin-based root canal sealer. This could weaken the sealer's bond to the tooth tissues, causing microleakage, and other problems. For these reasons, residual monomer release and incomplete polymerization of the resin-based root canal sealer is important for the clinicians.

This study aimed to evaluate the amount of UDMA, Bis-GMA, poly (ethylene glycol) dimethacrylate (PEGDMA), and 2-hydroxyethyl methacrylate (HEMA) eluted from the resin-based root canal sealer Epiphany using HPLC. The null hypothesis tested was that the polymerized root canal sealer does not elute residual monomer.

\section{MATERIALS AND METHODS}

Table 1 shows the composition of the dimethacrylate monomers and resin-based root canal sealer used in this study.

\section{Preparation of specimens}

Resin-based root canal sealer (Epiphany, Pentron Clinical Technologies, Wallingford, CT, US) was prepared according to manufacturer's instructions and placed into the plastic molds approximately $2 \mathrm{~mm}$ in height and $3 \mathrm{~mm}$ in diameter. Mylar matrix strip and glass slide were placed above the specimens and light-cured with light emitting diode (LED) (Elipar

\begin{tabular}{|c|c|c|c|}
\hline Materials & Manufacturer & $\begin{array}{c}\text { Lot } \\
\text { number }\end{array}$ & Composition \\
\hline HEMA & Aldrich Chemical Co. & 477028 & HEMA \\
\hline UDMA & Aldrich Chemical Co. & 436909 & UDMA \\
\hline Bis-GMA & Aldrich Chemical Co. & 494356 & Bis-GMA \\
\hline PEGDMA & Aldrich Chem Co. & 409510 & PEGDMA \\
\hline Bis-EMA & Aldrich Chem. Co. & 03514HF & Bis-EMA \\
\hline Epiphany & $\begin{array}{l}\text { Pentron Clinical } \\
\text { Technologies }\end{array}$ & 149468 & $\begin{array}{l}\text { Mixture of UDMA, } \\
\text { PEGDMA, EBPADMA } \\
\text { and Bis-GMA resins, } \\
\text { silane-treated barium- } \\
\text { borosilicate glasses, } \\
\text { aluminum oxide, barium } \\
\text { sulfate, silica, calcium } \\
\text { hydroxide, bismuth } \\
\text { oxychloride with amines, } \\
\text { peroxide, photo initator, } \\
\text { stabilizers, and pigment }\end{array}$ \\
\hline
\end{tabular}

HEMA: 2-hydroxyethyl methacrylate, UDMA: Urethane dimethacrylate, Bis-GMA: Bisphenol A-glycidyl methacrylate, PEGDMA: Poly (ethylene glycol) dimethacrylate, Bis-EMA: Bisphenol A ethoxylated dimethacrylate

Freelight 2,3MESPE Dental Products, St. Paul, MN, US) for $40 \mathrm{~s}$ exposures with a standard mode. The output of the LED was $1200 \mathrm{~m} \mathrm{~W} / \mathrm{cm}^{2}$. Twenty-four specimens were prepared. Immediately, after the curing process, the specimens were taken out from the molds and separated into two groups. The first group $(n=12)$ was immersed in Eppendorf tubes containing 200 $\mu l$ phosphate-buffered saline solution (PBS) and incubated at $37^{\circ} \mathrm{C}$ for $45 \mathrm{~s}$, the second group $(n=12)$ got the same treatment, but for $24 \mathrm{~h}$.

High-performance liquid chromatography analyses Stock solutions containing $1000 \mu \mathrm{g} / \mathrm{mL}$ for each monomer were diluted with methanol and calibration standards were prepared by proper dilution of the stock solution. Final concentration of the standards for HEMA, UDMA, and Bis-GMA were 0.025, 0.05, $0.1,0.2,0.5$, and $1 \mu \mathrm{g} / \mathrm{mL}$; those for PEGDMA were $0.0005,0.001,0.0015,0.002$, and $0.0025 \mu \mathrm{g} / \mathrm{mL}$; those for Bis-EMA were 2.5, 5, 10, 15, 20, 45, and $70 \mu \mathrm{g} / \mathrm{mL}$. Calibration graphs for monomers were obtained. The calibration graph for HEMA, UDMA, and Bis-GMA was seen in Figure 1; that for PEGDMA and Bis-EMA was seen in Figure 2. $100 \mu \mathrm{L}$ of the specimen extracts were subjected to HPLC (Agilent Technologies 1200S, Santa Clara, CA, USA). The stationary phase was C18, $150 \times 4.6 \mathrm{~mm}^{2}$ with $5-\mu \mathrm{m}$ particle size. The mobile phase was methanol/water $(60 / 40 \% \mathrm{v} / \mathrm{v}$ between 0 and $8 \mathrm{~min}$ and $75 / 25 \% \mathrm{v} / \mathrm{v}$ after $8 \mathrm{~min}$ ) at a flow rate of $1 \mathrm{ml} / \mathrm{min}$. The determination was made at a wavelength of $210 \mathrm{~nm}$. Detection and quantitative analysis of components were done by comparing the elution time and the integration of 


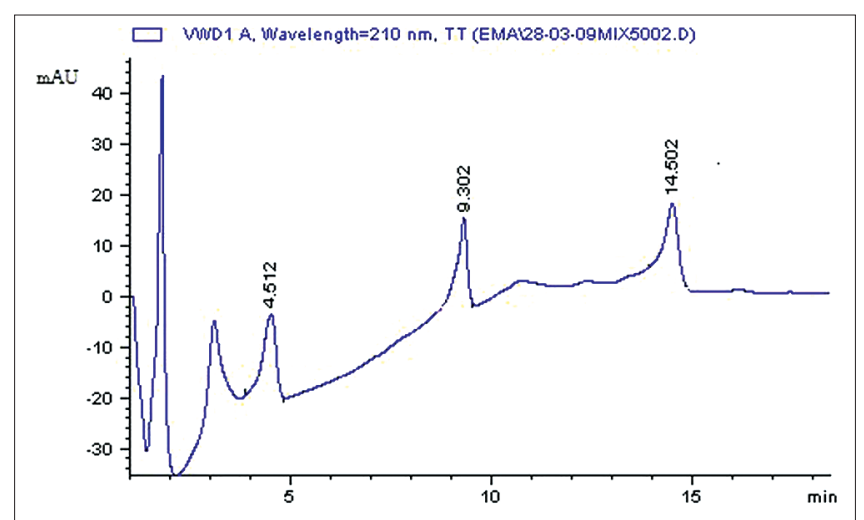

Figure 1: The calibration graph for 2-hydroxyethyl methacrylate, urethane dimethacrylate and bisphenol A-glycidyl methacrylate

absorption peak area of elutes with those of the authentic sample. The HPLC analysis was repeated three times. One-way analysis of variance was used to analyze data $(P<0.05)$. Linear calibration equations were given in Table 2.

\section{RESULTS}

The retention time of HPLC peaks of the standard solution of HEMA, UDMA, Bis-GMA, PEGDMA, and Bis-EMA was determined as 4.512, 9.302, 14.502, 5.004, and $10.153 \mathrm{~min}$, respectively [Figures 1 and 2]. Table 3 illustrates the average values of eluted monomers. All samples released HEMA, UDMA, Bis-GMA, PEGDMA, and Bis-EMA. Statistical analysis revealed that the quantity of residual monomer values varied according to the time periods (45 min and $24 \mathrm{~h}$ ). A significant difference was determined between the residual monomer values of HEMA, UDMA, PEGDMA, and Bis-EMA at $45 \mathrm{~min}$ and $24 \mathrm{~h}(P=0.000)$. On the other hand, no significant difference was determined between the residual monomer amounts of Bis-GMA $(P=0.331)$.

\section{DISCUSSION}

Resin-based root canal sealing materials are promoted as substitutes for conventional Gutta-percha due to their sealing abilities and reinforcement of the root canal space. ${ }^{[17-21]}$ Although endodontic sealers are proposed to be limited to the root canal, their extrusion can be seen through the apical foramina during placement. ${ }^{[25]}$ When not extruded, they are frequently in direct contact with the adjacent periradicular tissues. The long-term reactions of periradicular tissues to cytotoxic materials may delay periapical healing, and cause endodontic treatment to fail. ${ }^{[23,24]}$ Thus, the biocompatibilities of endodontic sealers are important to the treatment's success.

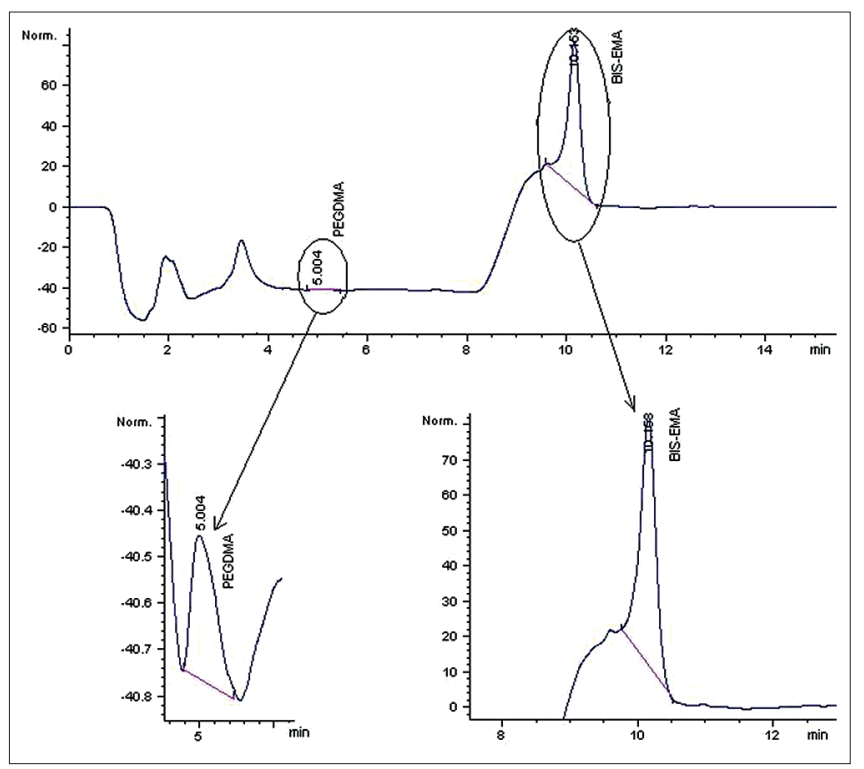

Figure 2: The calibration graph for poly (ethylene glycol) dimethacrylate and bisphenol A ethoxylated dimethacrylate

\begin{tabular}{lccc}
\multicolumn{4}{l}{ Table 2: Linear calibration equations for monomers } \\
\hline Monomer & $\boldsymbol{\lambda}(\mathbf{n m})$ & $\boldsymbol{R}^{\mathbf{2}}$ & Equation \\
\hline HEMA & 210 & 0.998 & $\mathrm{y}=153.0 \mathrm{x}-2.885$ \\
UDMA & 210 & 0.999 & $\mathrm{y}=112.1 \mathrm{x}-0.880$ \\
Bis-GMA & 210 & 0.999 & $\mathrm{y}=190.12 \mathrm{x}-0.71$ \\
PEGDMA & 210 & 0.997 & $\mathrm{y}=361.8 \mathrm{x}-0.221$ \\
Bis-EMA & 210 & 0.997 & $\mathrm{y}=98.73 \mathrm{x}-262.0$
\end{tabular}

HEMA: 2-hydroxyethyl methacrylate, UDMA: Urethane dimethacrylate, Bis-GMA: Bisphenol A-glycidyl methacrylate, PEGDMA: Poly (ethylene glycol) dimethacrylate, Bis-EMA: Bisphenol A ethoxylated dimethacrylate

Table 3: The mean values of eluted monomers at
$\mathbf{4 5}$ min and $\mathbf{2 4 ~} \mathrm{h}$
\begin{tabular}{lcc}
\hline Monomer & $\mathbf{4 5} \mathbf{~ m i n}$ & $\mathbf{2 4 ~ h}$ \\
\hline HEMA & $0.1025 \mathrm{ppm}^{\mathrm{a}}$ & $0.6442 \mathrm{ppm}^{\mathrm{b}}$ \\
UDMA & $0.0889 \mathrm{ppm}^{\mathrm{a}}$ & $0.2764 \mathrm{ppm}^{\mathrm{b}}$ \\
Bis-GMA & $0.0491 \mathrm{ppm}^{\mathrm{a}}$ & $0.0577 \mathrm{ppm}^{\mathrm{b}}$ \\
PEGDMA & $0.000682 \mathrm{ppm}^{\mathrm{a}}$ & $0.002469 \mathrm{ppm}^{\mathrm{b}}$ \\
Bis-EMA & $4.029812 \mathrm{ppm}^{\mathrm{a}}$ & $32.61282 \mathrm{ppm}^{\mathrm{b}}$
\end{tabular}

${ }^{*}$ Cases represent the significant differences between the time.

HEMA: 2-hydroxyethyl methacrylate, UDMA: Urethane dimethacrylate, Bis-GMA: Bisphenol A-glycidyl methacrylate, PEGDMA: Poly (ethylene glycol) dimethacrylate, BiS-EMA: Bisphenol A ethoxylated dimethacrylate

Theoretically, the resin-based material might have all of its monomer polymerized, but investigates have indicated that $25-50 \%$ of methacrylate monomer double bonds remain intact named as residual monomers. ${ }^{[26]}$ Leaching of residual monomers from resin-based materials can also harm biocompatibility. ${ }^{[7,27]}$ Geurtsen et al..$^{[7]}$ evaluated the cytotoxicity of 35 dental resin monomers and reported that TEGDMA, Bis-GMA, UDMA, and Bis-EMA are particularly cytotoxic on human fibroblasts in vitro. Furthermore, HEMA was 
found to be cyto-and genotoxic and could lead to adverse influences in patients. ${ }^{[6]}$ Although there are lots of studies on the substances released from dental resin composites, little information is available about the elution process of unreacted monomer from new dual-cure resin-based root canal sealer (Epiphany). The current study evaluated the time-related elution of Bis-GMA, UDMA, Bis-EMA, HEMA, and PEGDMA from Epiphany. HPLC method determined the quality and quantity of residual monomers eluted from resin-based materials. ${ }^{[9,16]}$

After the HPLC analyses, this current study showed that all of the samples released UDMA, Bis-GMA, PEGDMA, Bis-EMA, and HEMA in both time periods, even though the manufacturer claimed dual-cure resin-based sealer Epiphany contained only Bis-GMA, UDMA, and PEGDMA monomers. However, the amount of these monomers is under the toxic values relative to that were reported in the previous cytotoxicity studies. ${ }^{[6,7]}$ Yoshii ${ }^{[6]}$ evaluated the cytotoxicity of monomers used in dental materials to determine cytotoxic levels of dental resin materials and found $\mathrm{IC}_{50}$ values as 10.07, 0.09, 0.03, and $29.26 \mathrm{mM} / \mathrm{L}$ for HEMA, UDMA, Bis-GMA, and Bis-EMA respectively. In a similar study, Geurtsen et al. ${ }^{[7]}$ found ED50 values of HEMA, UDMA, Bis-GMA, and Bis-EMA in different cell cultures as, 1.77-2.52, $0.06-0.47,0.08-0.14$, and $0.21-0.78 \mathrm{mM} / \mathrm{L}$ respectively. In the current study, the amount of detected monomers were $7.88 \times 10^{-4}, 1.88 \times 10^{-4}, 0.9 \times 10^{-4}$, and $89 \times 10^{-4} \mathrm{mM} / \mathrm{L}$ in 45-min extracts and $49 \times 10^{-4}, 5.86 \times 10^{-4}, 1.0105 \times 10^{-4}$, $72 \times 10^{-3} \mathrm{mM} / \mathrm{L}$ in $24-\mathrm{h}$ extracts for HEMA, UDMA, Bis-GMA, and Bis-EMA respectively when the ppm values converted to $\mathrm{mM} / \mathrm{L}$.

This study used dual-cure resin-based root canal sealer, which contains components for both photo-activated and chemically activated reaction. LED, used for $40 \mathrm{~s}$ as the manufacturer instructed initiated photopolymerization. Type of resin-based material and light-curing unit are among the factors affecting resin polymerization. ${ }^{[28]}$ Hence, as to succeed the acceptable polymerization to overcome the residual monomer, the effects of different curing units and increasing the irradiation time have been studied, extensively. ${ }^{[9,28-30]}$ Increased irradiation time from 30 to $50 \mathrm{~s}$ significantly decreases residual monomer content and quantity. ${ }^{[31]}$ In the current study, the effect of different light-curing units and irradiation time on residual monomer release of Epiphany root canal sealer was not analyzed. These effects should be determined in future studies.
Another parameter that affects the amount is the solvent used for the elution. Various solvents such as distilled water, saliva, ethanol, methanol, or acetonitrile have been used in previous HPLC studies. ${ }^{[2,32]}$ Organic solvents such as ethanol, methanol, or mixtures of these solvents with water are chosen to simulate oral conditions. However, in the current study, as the resin-based root canal sealer contacts the periapical tissues in clinical conditions, PBS was used as a solvent for elution due to its similarity to tissue fluid.

Moreover, there is an opposing opinion on the necessary time for the whole elution of the extractable quantity of unreacted monomers in the literature..$^{[9,30,33]}$ Some investigations have proposed that elution is finished in 1-7 days, whereas other ones indicated that it continues for a long time..$^{[1,933]}$ Kawahara et al. ${ }^{[32]}$ reported the elution of residual monomer at time intervals of $1,3,6,12$, and $24 \mathrm{~h}$ and 3,7 , and 14 days by HPLC. Sideridou and Achilias ${ }^{[29]}$ determined the amount of residual monomer at several time intervals from $3 \mathrm{~h}$ to 30 days. In the current study, the specimens were incubated for $45 \mathrm{~min}$ and $24 \mathrm{~h}$. According to manufacturer information, Epiphany root canal sealer is fully polymerized in $45 \mathrm{~min}$ after photopolymerization. In addition, these two time periods ( $45 \mathrm{~min}$ and $24 \mathrm{~h}$ immersion periods) were used to compare the early and late elution of monomers from the dual-cured resin-based sealer.

Within the limitations of this study, the null hypothesis was rejected, because the results showed that residual monomer elution continued for $24 \mathrm{~h}$, which indicates the polymerization process of the dual-cure resin-based material cannot be completed in $45 \mathrm{~min}$.

Longer time intervals for the elution of unreacted monomer should be investigated in future studies. In addition, the experimental setup did not simulate an in vivo situation because the resin-based canal material was not used in the root canal. Future studies should evaluate the leaching of monomers from apical foramen.

\section{Acknowledgment}

This study was represented in IADR General Session, Barcelona, Spain, 2010.

\section{Financial support and sponsorship}

Nil.

\section{Conflicts of interest}

There are no conflicts of interest. 


\section{REFERENCES}

1. Jorge JH, Giampaolo ET, Machado AL, Vergani CE. Cytotoxicity of denture base acrylic resins: A literature review. J Prosthet Dent 2003;90:190-3.

2. Hensten-Pettersen A, Wictorin L. The cytotoxic effect of denture base polymers. Acta Odontol Scand 1981;39:101-6.

3. Nakamura M, Kawahara H. Long-term biocompatibility test of denture base resins in vitro. J Prosthet Dent 1984;52:694-9.

4. Lefebvre CA, Schuster GS, Caughman GB, Caughman WF. Effects of denture base resins on oral epithelial cells. Int J Prosthodont 1991;4:371-6

5. Moszner N, Ulrich S. New developments of polymeric dental composites. Prog Polym Sci 2001;26:535-76.

6. Yoshii E. Cytotoxic effects of acrylates and methacrylates: Relationships of monomer structures and cytotoxicity. J Biomed Mater Res 1997;37:517-24.

7. Geurtsen W, Lehmann F, Spahl W, Leyhausen G. Cytotoxicity of 35 dental resin composite monomers/additives in permanent 3T3 and three human primary fibroblast cultures. J Biomed Mater Res 1998;41:474-80

8. Reichl FX, Simon S, Esters M, Seiss M, Kehe K, Kleinsasser N, et al. Cytotoxicity of dental composite (co) monomers and the amalgam component $\mathrm{Hg}(2+)$ in human gingival fibroblasts. Arch Toxicol 2006;80:465-72

9. Munksgaard EC, Peutzfeldt A, Asmussen E. Elution of TEGDMA and BisGMA from a resin and a resin composite cured with halogen or plasma light. Eur J Oral Sci 2000;108:341-5.

10. Noda M, Komatsu H, Sano H. HPLC analysis of dental resin composites components. J Biomed Mater Res 1999;47:374-8.

11. Moon HJ, Lim BS, Lee YK, Kim CW. Determination of residual monomers in dental pit and fissure sealants using food/oral simulating fluids. Bull Korean Chem Soc 2000;21:1115-8.

12. Bagis $\mathrm{YH}$, Rueggeberg FA. The effect of post-cure heating on residual, unreacted monomer in a commercial resin composite. Dent Mater 2000:16:244-7.

13. Vaubert VM, Moon PC, Love BJ. Extractable free monomers from self-cured dental sealants resulting from dispensing errors. J Biomed Mater Res 1999;48:5-8

14. Dolez P, Marek M, Love BJ. Photopolymerizable acrylic resin: Effect of curing time and temperature. J Appl Polym Sci 2001;82:546-54.

15. Hamid A, Hume WR. A study of component release from resin pit and fissure sealants in vitro. Dent Mater 1997;13:98-102.

16. Tarumi H, Imazato S, Ehara A, Kato S, Ebi N, Ebisu S. Post-irradiation polymerization of composites containing bis-GMA and TEGDMA. Dent Mater 1999;15:238-42.

17. Resende LM, Rached-Junior FJ, Versiani MA, Souza-Gabriel AE, Miranda CE, Silva-Sousa YT, et al. A comparative study of physicochemical properties of AH plus, epiphany, and epiphany SE root canal sealers. Int Endod J 2009;42:785-93.

18. Karapinar Kazandag M, Sunay H, Tanalp J, Bayirli G. Fracture resistance of roots using different canal filling systems. Int Endod J 2009;42:705-10.
19. Monticelli F, Sword J, Martin RL, Schuster GS, Weller RN, Ferrari M, et al. Sealing properties of two contemporary single-cone obturation systems. Int Endod J 2007;40:374-85.

20. Fisher MA, Berzins DW, Bahcall JK. An in vitro comparison of bond strength of various obturation materials to root canal dentin using a push-out test design. J Endod 2007;33:856-8.

21. Monticelli F, Sadek FT, Schuster GS, Volkmann KR, Looney SW, Ferrari $\mathrm{M}$, et al. Efficacy of two contemporary single-cone filling techniques in preventing bacterial leakage. J Endod 2007;33:310-3.

22. Sjogren U, Hagglund B, Sundqvist G, Wing K. Factors affecting the long-term results of endodontic treatment. J Endod 1990;16:498-504.

23. Orstavik D, Kerekes K, Eriksen HM. Clinical performance of three endodontic sealers. Endod Dent Traumatol 1987;3:178-86.

24. Waltimo TM, Boiesen J, Eriksen HM, Ørstavik D. Clinical performance of 3 endodontic sealers. Oral Surg Oral Med Oral Pathol Oral Radiol Endod 2001;92:89-92.

25. Pommel L, Camps J. In vitro apical leakage of system B compared with other filling techniques. J Endod 2001;27:449-51.

26. Imazato S, McCabe JF, Tarumi H, Ehara A, Ebisu S. Degree of conversion of composites measured by DTA and FTIR. Dent Mater 2001;17:178-83.

27. Wataha JC, Hanks CT, Strawn SE, Fat JC. Cytotoxicity of components of resins and other dental restorative materials. J Oral Rehabil 1994;21:453-62

28. Ak AT, Alpoz AR, Bayraktar O, Ertugrul F. Monomer Release from Resin Based Dental Materials Cured With LED and Halogen Lights. Eur J Dent 2010;4:34-40.

29. Sideridou ID, Achilias DS. Elution study of unreacted Bis-GMA TEGDMA, UDMA, and Bis-EMA from light-cured dental resins and resin composites using HPLC. J Biomed Mater Res B Appl Biomater 2005;74:617-26

30. Tabatabaee MH, Mahdavi H, Zandi S, Kharrazi MJ. HPLC analysis of eluted monomers from two composite resins cured with LED and halogen curing lights. J Biomed Mater Res B Appl Biomater 2009;88:191-6.

31. Tanaka K, Taira M, Shintani H, Wakasa K, Yamaki M. Residual monomers (TEGDMA and Bis-GMA) of a set visible-light-cured dental composite resin when immersed in water. J Oral Rehabil 1991;18:353-62.

32. Kawahara T, Nomura Y, Tanaka N, Teshima W, Okazaki M, Shintani H Leachability of plasticizer and residual monomer from commercial temporary restorative resins. J Dent 2004;32:277-83.

33. Altintas $\mathrm{SH}$, Usumez A. Evaluation of TEGDMA leaching from four resin cements by HPLC. Eur J Dent 2012;6:255-62.

\begin{tabular}{|l|l|}
\hline \multicolumn{2}{|c|}{ Access this article online } \\
\hline Quick Response Code: & \\
\hline
\end{tabular}

